\title{
Cloning and nucleotide sequence of the Butyrivibrio fibrisolvens gene encoding a type III glutamine synthetase
}

\author{
Heide J. K. Goodman and David R. Woods* \\ Department of Microbiology, University of Cape Town, Rondebosch 7700, South Africa
}

(Received 5 January 1993; revised 26 February 1993; accepted 15 March 1993)

\begin{abstract}
A Butyrivibrio fibrisolvens glnA gene encoding glutamine synthetase (GS) was cloned on a recombinant plasmid pGS4 which enabled Escherichia coli gln $A$ deletion mutants to utilize $\left(\mathrm{NH}_{4}\right)_{2} \mathrm{SO}_{4}$ as a sole source of nitrogen. The nucleotide sequence of a 2423 bp DNA segment containing the GS-coding region of $B$. fibrisolvens was determined and the complete amino acid sequence (701 residues) was deduced. Comparisons of the derived $B$. fibrisolvens GS protein sequence with the amino acid sequences of GS from other bacteria indicate that it is the second reported example of a type III GS, originally identified in the obligate anaerobe Bacteroides fragilis. The presence of GS in $B$. fibrisolvens cells and the regulation of the cloned GS in $E$. coli cells was demonstrated by Western blot analysis.
\end{abstract}

\section{Introduction}

The genus Butyrivibrio is composed of Gram-negative anaerobic bacteria that ferment a wide variety of carbohydrates with the production of large amounts of butyric acid. Butyrivibrio fibrisolvens is a ubiquitously distributed bacterial species in the gastro-intestinal tracts of ruminants and other mammals.

Ammonia is the major and often a required source of nitrogen for most rumen bacteria (Bryant \& Robinson, 1962). Enzymes involved in the assimilation of ammonia are essential for the growth of most rumen organisms. In prokaryotes, glutamate dehydrogenase (GDH) and the dual enzyme system, glutamine synthetase (GS) and glutamate synthetase (GOGAT), are the two most important routes by which ammonia may be assimilated (Hespell, 1984).

There is a paucity of information concerning the pathways and regulation of ammonia assimilation in rumen organisms. Studies with ${ }^{15} \mathrm{NH}_{4}^{+}$have shown that bacterial amide is the most rapidly labelled nitrogen pool in the bacterial population of the rumen over a range of

*Author for correspondence. Tel. 21650 2183; fax 216504023 ; e-mail heide@micro.uct.ac.za.

Abbreviations: GS, glutamine synthetase; ORF, open reading frame.

The nucleotide sequence data reported in this paper have been submitted to GenBank and have been assigned the accession no. L08256. ruminal ammonia concentrations. These results imply that GS is an important route of ammonia assimilation in the bacterial population of the rumen (Smith et al., 1981)

Until recently, it appeared that prokaryotes had two forms of GS termed GSI and GSII. The majority of bacteria investigated have GSI-type enzymes but members of the Rhizobiaceae, Frankiaceae and Streptomyces contain both GSI- and GSII-type enzymes (Darrow \& Knotts, 1977; Kumada et al., 1990; Rochefort \& Benson, 1990). GSI is the typical prokaryotic GS (Streicher \& Tyler, 1980) whereas GSII is similar to eukaryotic GS enzymes (Carlson \& Chelm, 1986). The GS gene from the clinical isolate Bacteroides fragilis Bf-1 has been cloned (Southern et al., 1986), the nucleotide sequence determined (Hill et al., 1989), and the GS protein characterized (Southern et al., 1987). The GS from $B$. fragilis differs markedly from the GS enzymes of prokaryotes, eukaryotes and archaeobacteria. The holoenzyme is a single disc of six identical subunits with an $M_{\mathrm{r}}$ of approximately 490000 . The GSI and GSII holoenzymes are dodecamers and octamers, respectively. The $B$. fragilis GS subunit is large and has a calculated $M_{\mathrm{r}}$ of 82827 . It contains 729 amino acids, and is approximately 270 and 400 amino acids longer than the GSI and GSII subunits, respectively, of other prokaryotes and eukaryotes. Because of these differences, Hill et al. (1989) suggested that GS enzymes with large subunits arranged as hexamers should be grouped together to form a third class of GS enzyme termed 


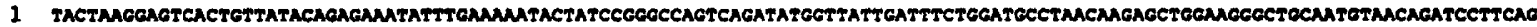

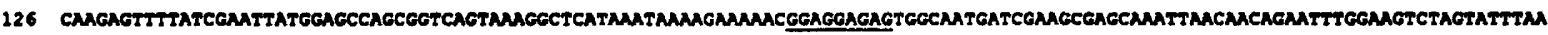

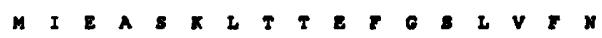

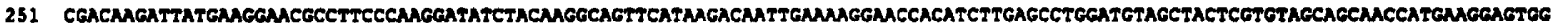

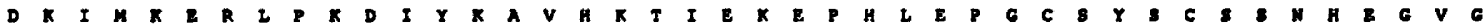

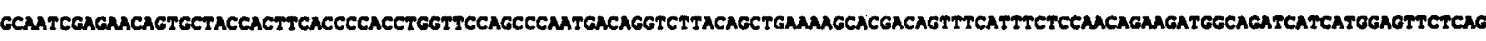

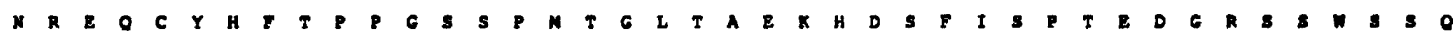

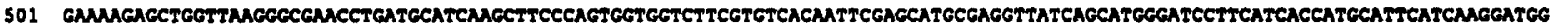

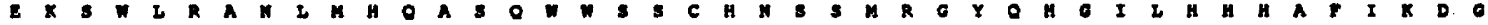

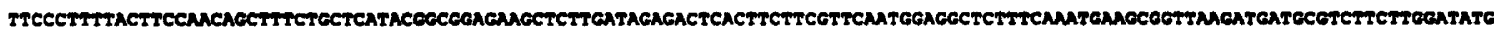

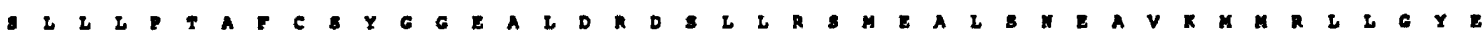

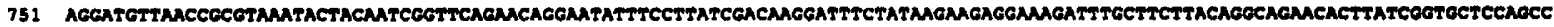
D V N I V N T I I G

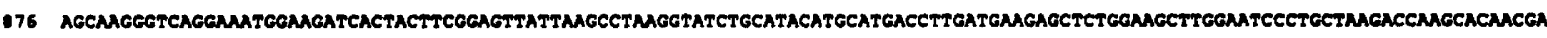

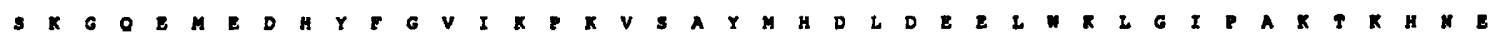

1001 GOTTGCACCTTCTCAGCACGAGCTGOCTCCTGTATPTGAGACAGCAMCATCGCTGTAGATCACAACCAGCTCACAATGgMGTTATGMGAGGTTGCTGACMAGACACTATECATGTCTTC VA P $\mathbf{P}$ O

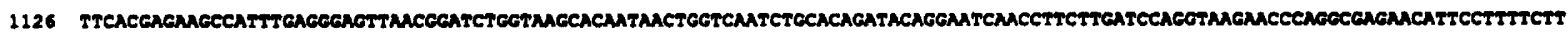

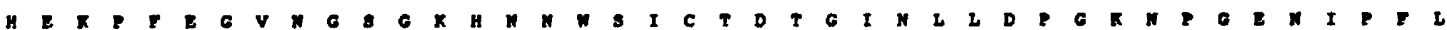

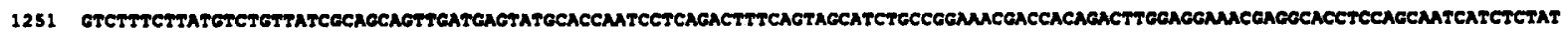

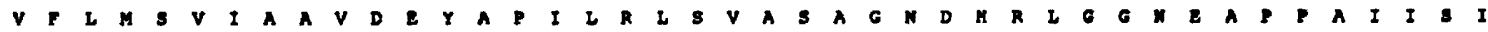

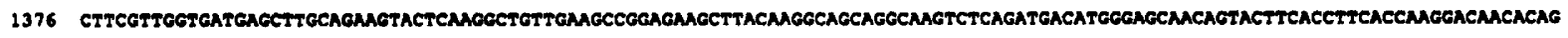

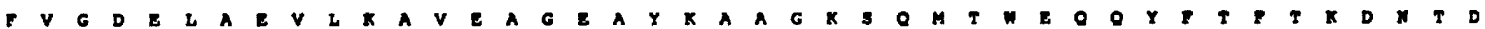

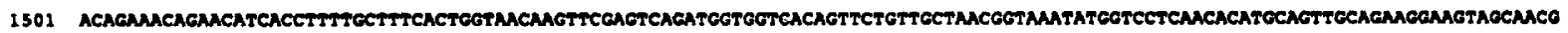

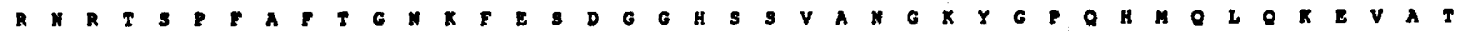

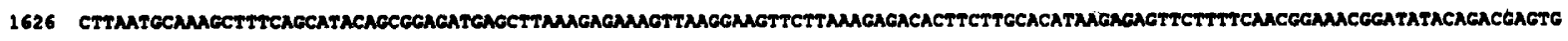

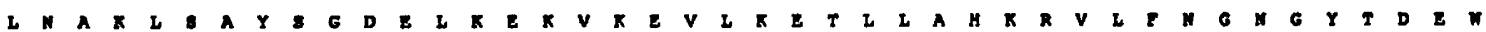

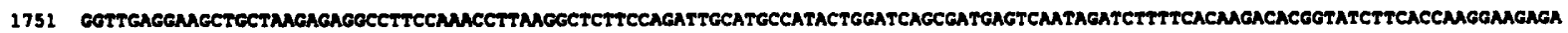
$V$ E E A A K R G L P N L K A L P D C M P Y W I S D E

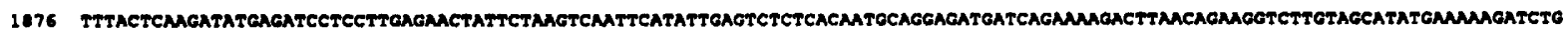

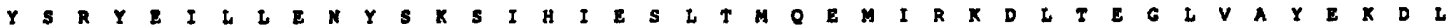

2001 TCAMAGAGATTETTCAGNAMAGACCCTTCTCGATGGAGACTGCTGTGCACTTGAGCTGGGATTCTTAAGTCTCTTGATAMGTCCAGCGCAGAGATGGGCAGGCACTTTCAMGCTCTTCGA

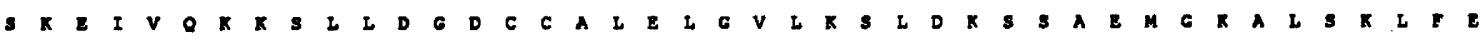

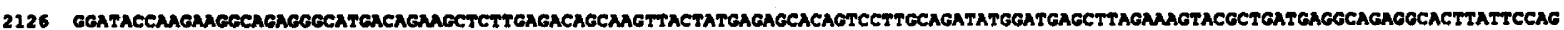

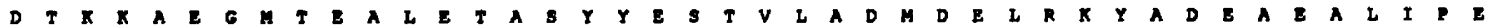

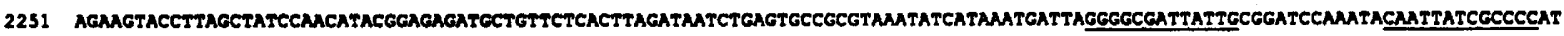

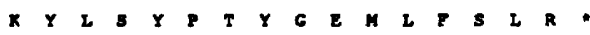

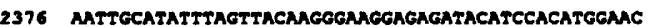


GSIII. We report the cloning and characterization of the $g \ln A$ gene from the rumen anaerobe $B$. fibrisolvens. This $g \ln A$ gene encodes a GS which is similar to the $B$. fragilis GS and is the second example of a GS which belongs to the GSIII class.

\section{Methods}

Bacterial strains, vectors, and growth conditions. Chromosomal DNA from B. fibrisolvens H17c (Dehority, 1966) was used for the cloning of the $B$. fibrisolvens $g \ln A$ gene. The E.coli host strain used for the original cloning experiment was the YMC11 $g \ln A$ deletion mutant (Backman et al., 1981). Subcloning and other genetic manipulations were carried out in E. coli LK111 (Zabeau \& Stanley, 1982). The E. coli-Bacillus subtilis shuttle vector $\mathrm{pEB} 1$, used for the construction of the $B$. fibrisolvens genomic library, has been described previously (Lin et al., 1990). Subcloning for sequencing was done using the high copy number pUCBM20 and -21 vectors (Boehringer Mannheim). B. fragilis strain Bf-1 was used by Southern et al. $(1986,1987)$ and Hill et al. (1989) for the cloning and molecular analysis of the $B$. fragilis gin $A$ gene. $B$. fibrisolvens $\mathrm{H} 17 \mathrm{c}$ was grown in M10 medium as described by Strydom et al. (1986). E. coli strains were grown in Luria-Bertani (LB) medium or glucose minimal medium (Miller, 1972) with $1 \mathrm{~g}\left(\mathrm{NH}_{4}\right)_{2} \mathrm{SO}_{4} \mathrm{I}^{-1}$ (GMMN) as the sole nitrogen source. Glucose minimal medium for nitrogen regulation studies contained $15 \mathrm{mM}$-glutamine (GMML) or $15 \mathrm{~mm}$-glutamine and $13 \mathrm{~mm}$-( $\left.\mathrm{NH}_{4}\right)_{2} \mathrm{SO}_{4}(\mathrm{GMMH})$. Ampicillin $(100 \mu \mathrm{g}$ $\mathrm{ml}^{-1}$ ) was added to media for plasmid selection and maintenance. $B$. fragilis $\mathrm{Bf}-1$ was grown on supplemented brain heart infusion (BHI) agar (Holdeman \& Moore, 1972) as described by Hill et al. (1989).

Preparation of DNA and recombinant DNA techniques. Construction of the $B$. fibrisolvens $\mathrm{H} 17 \mathrm{c}$ genomic library in $\mathrm{pEB} 1$ has been described (Lin et al., 1990). Plasmid DNA prepared from pools of clones containing $B$. fibrisolvens DNA was used to transform the $E$. coli YMC11 $\mathrm{g} \ln A$ deletion strain. An $E$. coli $\mathrm{YMC} 11 \mathrm{GlnA}^{+}$ampicillin resistant transformant was isolated on GMMN medium. DNA fragments for subcloning were purified from $0.8 \%(\mathrm{w} / \mathrm{v})$ agarose Tris/acetate gels by adsorption onto glass beads (Gene Clean). The preparation of plasmid DNA and restriction endonuclease mapping of the clones was done using standard techniques (Sambrook et al., 1989). B. fibrisolvens chromosomal DNA was prepared as described by Berger et al. (1989) and Southern hybridization was used to confirm that the insert DNA originated from $B$. fibrisolvens.

Nucleotide sequence determination and analysis. The Exo-III mung bean nuclease technique was used to create a deletion series for sequencing (Henikoff, 1984). The nucleotide sequence of the $g \ln A$ gene was determined by the dideoxy-chain termination method using the Sequenase $2.0 \mathrm{kit}$ (US Biochemical Corp.) according to the manufacturer's specifications. The nucleotide and deduced amino acid sequences were analysed using the Genetics Computer Group Inc. software package (version 7.0). All the current databases accompanying the GCG package were screened for related nucleotide and amino acid sequences.

Western immunoblotting. Western blotting from SDS-PAGE gels onto nitrocellulose membranes was done by the method of Towbin et al. (1979). B. fragilis GS antibody binding and the development of bands using a goat anti-rabbit serum conjugated to horse-radish peroxidase were done as described previously (Southern et al., 1987).

\section{Results and Discussion}

Cloning and expression of a GS gene from $B$. fibrisolvens in E.coli

The $E$. coli $g \ln A$ deletion strain YMC11 was transformed with the genomic library of $B$. fibrisolvens. An E. coli YMC11 GlnA $A^{+}$transformant was isolated on GMMN agar plates containing ampicillin. The resident plasmid was designated pGS4 and was shown to harbour a $6 \cdot 1 \mathrm{~kb}$ insert of $B$. fibrisolvens DNA. A $5 \cdot 3 \mathrm{~kb}$ fragment of pGS4 insert DNA was subcloned in both orientations using the pUCBM20 and -21 sequencing vectors (pGS20 and pGS21, respectively). Both subclones retained GS activity. Hybridization of $\mathrm{HpaI}$ and $B g / \mathrm{II}$ fragments internal to the pGS20 insert to $B$. fibrisolvens $\mathrm{H} 17 \mathrm{c}$ chromosomal fragments of the same size confirmed the origin of the cloned DNA fragment (data not shown).

\section{Nucleotide sequence of the B. fibrisolvens glnA gene}

The nucleotide sequence of a $2423 \mathrm{bp}$ region of $B$. fibrisolvens DNA containing the $g \ln A$ gene was determined (Fig. 1). The DNA sequence contained an open reading frame (ORF) of 2103 nucleotides, which began with an ATG codon at position 201 and ended with a TAA codon at position 2303. The predicted size of the polypeptide encoded by this ORF was 701 amino acids, which has a calculated $M_{\mathrm{r}}$ of 79645 . A potential ribosomal binding sequence (GGAGGAGAG) was situated 6 bp upstream of the ATG initiation codon. No significant sequence homology was found upstream of the initiation codon with the canonical E. coli $\sigma 70$ promoter sequence or with the promoter consensus sequence for genes under $n t r$ control $(\sigma 54)$ (Dixon, 1984; Reitzer \& Magasanik, 1985). The B. fibrisolvens $g \ln A$ regulatory region was scanned for the presence of a consensus sequence similar to the consensus established for the binding of the $n \operatorname{tr} C$ gene product to the $g \ln A$ promoter region in enteric bacteria (Dixon, 1984). Such a sequence could not be found. A 13 bp inverted repeat sequence capable of forming a stem-loop structure was located $33 \mathrm{bp}$ downstream of the putative $g \ln A$ stop codon.

\section{Comparison of the translated amino acid sequence with sequences of GS enzymes from other organisms}

The degree of amino acid sequence homology between the $B$. fibrisolvens GS and those of other prokaryotes was determined on the basis of identical amino acid sequence

Fig. 1. (facing page). Nucleotide and deduced amino acid sequences of the B. fibrisolvens $g \ln A$ gene and flanking regions. The initiation codon ATG is at nucleotide 200 and the termination codon TAA is at nucleotide 2301. The derived amino acid sequence of 701 amino acids is given in the one letter code. The putative ribosome binding site and the inverted repeat sequence are underlined. 
Table 1. Comparison of the identity of the amino acid sequences of GS enzymes from various bacteria

The results are given as the percentage identity of the amino acid residues in the GS enzymes.

Sequence data of the proteins were taken from Hill et al. (1989) for B. fragilis (BFRA), Bozouklian \& Elmerich (1986) for Azospirillum brasilense (ABRA), Colonna-Romano et al. (1987) for Rhizobium leguminosarum (RLEG), Colombo \& Villafranca (1986) for $E$. coli (ECOL), Janson et al. (1986) for Salmonella typhimurium (STYP), Toukdarian et al. (1989) for Azotobacter vinelandii (AVIN), Cardy \& Murrell (1990) for Methylococcus capsulatus (MCAP), Rawlings et al. (1987) for Thiobacillus ferrooxidans (TFER), Tumer et al. (1983) for Anabaena sp. (ANAB), Nakano et al. (1989) for Bacillus cereus (BCER), Strauch et al. (1988) for B. subtilis (BSUB), Janssen et al. (1988) for Clostridium acetobutylicum (CACE), Possot et al. (1989) for Methanococcus voltae (MVOL) and B. fibrisolvens (BFIB) (this paper). The sequence data for Neisseria gonorrhoeae (NGON) were obtained from the GenBank databank (accession no. M84113).

\begin{tabular}{|c|c|c|c|c|c|c|c|c|c|c|c|c|c|c|}
\hline & BFRA & ABRA & RLEG & ECOL & STYP & AVIN & MCAP & TFER & NGON & ANAB & BCER & BSUB & CACE & MVOL \\
\hline BFIB & 40 & 22 & 25 & 24 & 25 & 21 & 22 & 21 & 22 & 24 & 26 & 24 & 22 & 22 \\
\hline BFRA & & 23 & 22 & 22 & 21 & 24 & 20 & 20 & 24 & 25 & 23 & 24 & 20 & 22 \\
\hline ABRA & & & 68 & 62 & 63 & 64 & 63 & 62 & 62 & 58 & 43 & 44 & 39 & 41 \\
\hline RLEG & & & & 64 & 64 & 64 & 63 & 58 & 57 & 56 & 41 & 41 & 39 & 39 \\
\hline ECOL & & & & & 97 & 69 & 68 & 65 & 63 & 55 & 44 & 43 & 42 & 39 \\
\hline STYP & & & & & & 69 & 69 & 65 & 63 & 55 & 44 & 44 & 42 & 40 \\
\hline AVIN & & & & & & & 71 & 67 & 65 & 53 & 42 & 43 & 42 & 41 \\
\hline MCAP & & & & & & & & 70 & 63 & 54 & 41 & 40 & 37 & 38 \\
\hline TFER & & & & & & & & & 64 & 55 & 42 & 41 & 39 & 37 \\
\hline NGON & & & & & & & & & & 54 & 39 & 40 & 38 & 39 \\
\hline ANAB & & & & & & & & & & & 35 & 38 & 36 & 38 \\
\hline BCER & & & & & & & & & & & & 86 & 62 & 51 \\
\hline BSUB & & & & & & & & & & & & & 64 & 52 \\
\hline CACE & & & & & & & & & & & & & & 52 \\
\hline
\end{tabular}

comparisons (Table 1). The highest amino acid sequence identity was obtained with the GS subunit sequence from B. fragilis ( $40 \%$ identity). An analysis of Table 1 places the GS enzymes from Gram-negative and Gram-positive organisms in separate clusters based on homology, with the GS enzymes from $B$. fibrisolvens and $B$. fragilis showing a greater divergence in sequence similarity.

Alignment of the predicted GS polypeptide sequences from $B$. fibrisolvens and $B$. fragilis revealed considerable homology in a number of highly conserved blocks, particularly in the central regions of the proteins (Fig. 2). The $B$. fibrisolvens GS is 28 amino acid residues shorter than the $B$. fragilis GS enzyme, with the majority of the missing amino acid residues being located at the $\mathrm{N}$ terminal end (residues 1-20) of the $B$. fragilis GS protein. Nevertheless, the two sequences share $40 \%$ amino acid identity when optimally aligned.

Five major regions of amino acid similarity between the prokaryotic type I and the eukaryotic type II GS enzymes have been identified (Rawlings et al., 1987). The active site of the type I GS is formed between enzyme subunits, and it has been shown that the five conserved amino acid regions are associated with the proposed GS active site (Almassy et al., 1986). Regions II to V are $\beta$ strands associated with two $\mathrm{Mn}^{2+}$ cations of one subunit while region I contains the tryptophan residue which is thought to complete the active site formed between adjacent subunits.

Hill et al. (1989) reported that these five regions were not strongly conserved in the $B$. fragilis GS protein, but they were able to identify regions I, II, III and V which showed some similarity to the corresponding regions in the GSI and GSII proteins (Fig. 2).

In a comparison with the GSI and GSII enzymes, only two of the five major regions of homology (regions II and III) could be identified in the GS enzyme from $B$. fibrisolvens (Fig. 2). Hill et al. (1989) reported that region II of all GSI and GSII enzymes contained four highly conserved amino acids which are not contiguous $\left[\mathrm{EV}\left(\mathrm{X}_{3-4}\right) \mathrm{Q}\left(\mathrm{X}_{1}\right) \mathrm{E}\right]$. These four amino acids are also conserved in region II of the $B$. fibrisolvens GS. Region III is considered to be the ATP-binding site because the sequence resembles the sequence KXXXXGXXGXGKT found in several ATP-binding proteins (Walker et al., 1982; Tischer et al., 1986). In region III of the $B$. fibrisolvens GS enzyme, an ATP-binding sequence can be identified. Furthermore, region III contains seven amino acid residues (KPXXXXNGXGXHXXXS) which are conserved in the ten eukaryote and prokaryote GS enzymes investigated (Hill et al., 1989), as well as in the GS enzymes from Azospirillum brasilense (Bozouklian \& Elmerich, 1986), Azotobacter vinelandii (Toukdarian et al., 1990), Bacillus cereus (Nakano et al., 1989), E. coli (Colombo \& Villafranca, 1986), Methylococcus capsulatus (Cardy \& Murrell, 1990) and Rhizobium leguminosarum (Colonna-Romano et al., 1987). In all GS enzymes investigated, the spacing between regions II and III is also highly conserved and is approximately 42 amino acid residues.

An important difference between the prokaryotic GSI 
214 LLTGRTLIGAPASKGQEMEDHYFGVIKP KVSAYMHDLDEELWKLG IPAKTKHNEVAP SQHELAPVFETANIAVDHNOLTMEVMKKVADKHNYACLLHEXPFEGVNGSGKHNNWSICTDTG

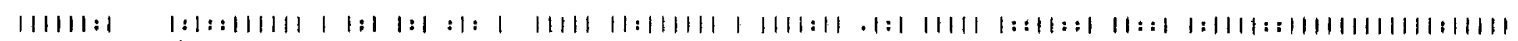
BERA 233 RLTGRTLMGHSSAKDQQLEDHYFGS IPPRVTAFMKELEIECHKLGIPVKTRHNEVAPNQFELAPIFENCNLANDHNQLVMDLMKRIARKHHFAVLFHEKPYNGVNGSGKHNNWSLCTDTG BFIB 334 INLLDPGKNPGENIPELVELMSVIAAVDEYAP ILRLSVASAGNDHRLGGNEAPPAIISIFVGDELAEVLKAVEAGEAYKAAGKSOMTWEQRY...FTFTK. ..... DNTDRNRTSPFAET

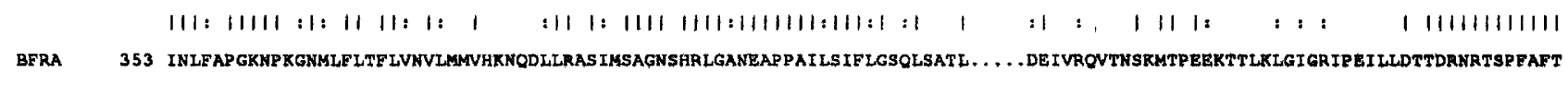
BFIB 445 GNKFESDGGHSSV.ANGKYGPQHMQLOKEVATLNARLSAYSGDEL. .KEKVKEVLKETLLAHKRVLFNGNGYTDEWVEEAAKRGLPNLKALPDCMPYWISDESIDLFTRHGIFTKREIYS

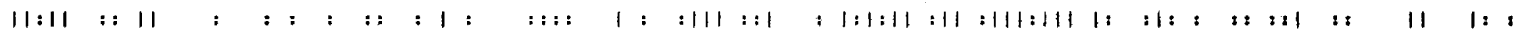
BFRA 468 GNREEFRAGSSANCAAAMIAINAAMANQLNEFKASVDKLMEEGIGKDEAIFRI LKENI IASELIRFEGDGYSEEWKQEAARGLTNICHVPEALMHYMDKQSRAVIGERIFNETELAC .region 5 .

BFIB 562 RYEILLENYSKS IHIESLTMQEMIRKDLTEGLVAYEKDLSKE IVOKKSLLDGDCCALELGVLKSLDKSSAEMGKALSKL. . FEDTKKAEGMTEAL.ETASYYESTVLADMDELRKYADE

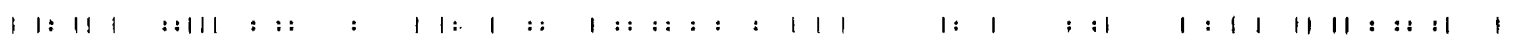

BFRA 588 RLEVELEKYTMKVQIESRVLGDIAINHIVR IAVSYONRLLENLCRMRE IFSEEEYEVMSADRKELIKEISHRVSAIKVLVRDWTEARKVANHKENFKEKAFAYEETVRPYLESIRDHIDH

BFIB 678 AEALIPEKYLSYPTYGEMLFSLR*

$11:: 111: 11$

BFRA 708 LEMEIDDEIWPLPKYRELLFTK*.
\end{abstract}

Fig. 2. Alignment of amino acid sequences of GS proteins from B. fibrisolvens (BFIB; this paper) and B. fragilis (BFRA; Hill et al., 1989). The underlined regions are the regions identified in the $B$. fragilis polypeptide sequence by Hill et al. (1989) showing homology with type I and type II GS subunits.

and the prokaryotic GSIII enzymes is that the former contains a tryptophan residue, or the functionally similar phenylalanine residue, at the position corresponding to position 139 in region I of the $B$. fibrisolvens GS, which is associated with the active site (Almassy et al., 1986; Hill et al., 1989). In the GSIII enzymes, the tryptophan is replaced by either valine, in the $B$. fragilis GS protein, or isoleucine in the $B$. fibrisolvens GS protein. These two amino acids are themselves functionally similar, but they show no functional similarity with tryptophan.

Region IV is thought to be the glutamate-binding site, but neither the $B$. fragilis nor $B$. fibrisolvens GS enzymes show convincing similarity with the other GS enzymes in region IV and region IV cannot be identified in the $B$. fragilis or $B$. fibrisolvens GS enzymes. Region $\mathrm{V}$ was identified in the $B$. fragilis GS by relatively high similarity with region V of the Streptomyces coelicolor GS (Hill et al., 1989). However, the B. fibrisolvens GS shows no convincing similarity with the $B$. fragilis or other GS enzymes in region $\mathrm{V}$ (Fig. 2).

The GSIII enzyme from B. fragilis is not regulated by adenylylation (Southern et al., 1987) and does not contain an 18-amino-acid sequence containing a tyrosine residue which has been shown to be the site of adenylylation in GSI enzymes (Shapiro \& Stadtman, 1968; Almassy et al., 1986; Hill et al., 1989). An 18amino-acid sequence containing tyrosine which even remotely resembles the GSI adenylylation region could not be identified in the $B$. fibrisolvens GS. The $B$. fibrisolvens GS appears to be the second example of a GS from a Gram-negative bacterium which is not regulated by adenylylation.

\section{Detection of GS in crude cell extracts by Western blotting}

Since the $B$. fragilis GS showed homology to the $B$. fibrisolvens GS, an antiserum raised against the purified $B$. fragilis GS was tested to determine whether it reacted with the $B$. fibrisolvens GS. The $B$. fragilis GS antiserum detected a single polypeptide with an apparent $M_{\mathrm{r}}$ of approximately 75000 in crude cell extracts of $B$. fragilis cells, B. fibrisolvens cells and $E$. coli YMC11(pGS4) cells (Fig. $3 a, b$ ). Previously, we showed that the $B$. fragilis 


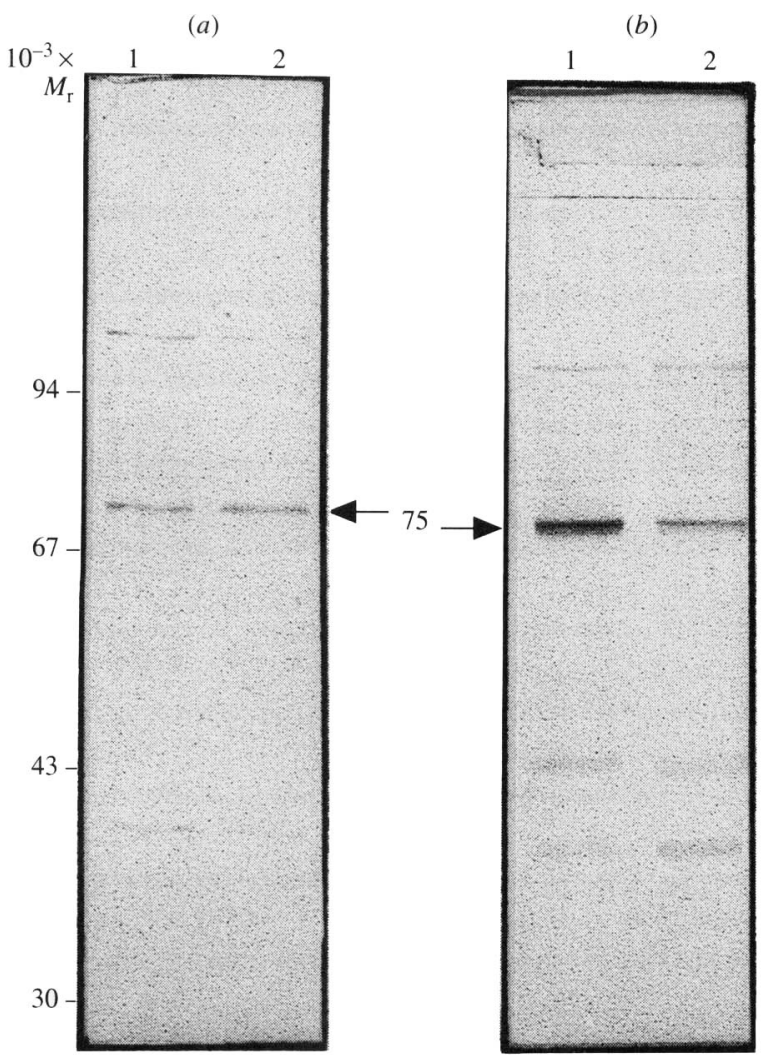

Fig. 3. Western blots of crude extracts from $B$. fibrisolvens, $B$. fragilis and $E$. coli YMC11(pGS4) cells. The SDS-PAGE-fractionated proteins were transferred to nitrocellulose paper and reacted with antiserum prepared against purified samples of the cloned $B$. fragilis GS. (a) Crude extracts ( $5 \mu \mathrm{g}$ protein) of $B$. fibrisolvens (lane 1$)$ and $B$. fragilis (lane 2) cells. (b) Crude extracts ( $25 \mu \mathrm{g}$ protein) of E. coli YMC11(pGS4) grown in GMML (lane 1) and GMMH (lane 2) medium.

antiserum did not react with any SDS-PAGE fractionated proteins from E. coli YMC11 cells (Southern et al., 1987). It appears that the production of the cloned B. fibrisolvens GS is regulated in E.coli YMC11 cells since the production of the $B$. fibrisolvens GS was induced by growth of $E$. coli YMC11(pGS4) cells in nitrogen-limiting GMML medium (Fig. $3 b$ ). Although $E$. coli YMC11 is a heterologous host, the fact that the production of the $B$. fibrisolvens GS appears to be regulated in $E$. coli YMC11 will be helpful in studying the regulation of expression of the $B$. fibrisolvens $g \ln A$ gene. Studies on the regulation of GS activity in $B$. fibrisolvens are not feasible at present, since a suitable nitrogenlimiting medium which supports the growth of $B$. fibrisolvens is not available.

\section{Conclusion}

Although the establishment of the novel type-III class of GS is justified on the characterization of a single GS from $B$. fragilis, the demonstration that this GS type is present in other bacteria is important in confirming and extending the relevance and importance of GSIII in prokaryotes. The GS from $B$. fibrisolvens can be assigned to the GSIII class because of its very large subunit size, and amino acid sequence and antigen homology with the $B$. fragilis GS. Size and amino acid sequence homology differentiate the $B$. fragilis and $B$. fibrisolvens GSIII enzymes from enzymes belonging to the GSI and GSII classes. The GSIII enzyme has been demonstrated in two diverse members of the family Bacteroidaceae which inhabit similar environments. It will be interesting to determine whether other members of the Bacteroidaceae have the GSIII enzyme and whether this different GS is a distinguishing characteristic of this bacterial family.

\section{References}

Almassy, R. J., Janson, C. A., Hamlin, R., Xuong, N. H. \& EISENBERG, D. (1986). Novel subunit-subunit interactions in the structure of glutamine synthetase. Nature, London 233, 304-309.

Backman, K., Chen, Y.-M. \& Magasanik, B. (1981). Physical and genetic characterization of the $g \ln A-g \ln G$ region of the Escherichia coli chromosome. Proceedings of the National Academy of Sciences of the United States of America 84, 4767-4771.

Berger, E., Jones, W. A., Jones, D. T. \& WoOds, D. R. (1989). Cloning and sequencing of an endoglucanase (endI) gene from Butyrivibrio fibrisolvens $\mathrm{H} 17 \mathrm{c}$. Molecular and General Genetics 219, 193-198.

Bryant, M. P. \& Robinson, I. M. (1962). Some nutritional characteristics of predominant culturable ruminal bacteria. Journal of Bacteriology 84, 605-614.

Bozouklian, H. \& ElmERICH, C. (1986). Nucleotide sequence of the Azospirillum brasilense $\mathrm{Sp} 7$ glutamine synthetase structural gene. Biochimie 68, 1181-1187.

Cardy, D. L. \& Murrell, J. C. (1990). Cloning, sequencing and expression of the glutamine synthetase structural gene $(g \ln A)$ from the obligate methanotroph Methylococcus capsulatus (Bath). Journal of General Microbiology 136, 343-352.

CARLSON, T. A. \& CHELM, B.K. (1986). Apparent eukaryotic origins of glutamine synthetase II from the bacterium Bradyrhizobium japonicum. Nature, London 322, 568-570.

Colombo, G. \& Villafranca, J. J. (1986). Amino acid sequence of Escherichia coli glutamine synthetase deduced from the DNA nucleotide sequence. Journal of Biological Chemistry 261, 10587-10591.

Colonna-Romano, S., Riccio, A., Guida, M., Defez, R., Lamberti, A., IAcCarino, M., Arnold, W., Priefer, U. \& Puhler, A. (1987) Tight linkage of $g \ln A$ and a putative regulatory gene in Rhizobium leguminosarum. Nucleic Acids Research 15, 1951-1964.

Darrow, R. A. \& KNOTTS, R.R. (1977). Two forms of glutamine synthetase in free-living root nodule bacteria. Biochemical and Biophysical Research Communications 78, 554-559.

DeHORITY, B. A. (1966). Characterization of several bovine rumen bacteria isolated with a xylan medium. Journal of Bacteriology 91, 1724-1729.

Dixon, R. (1984). Tandem promoters determine regulation of the Klebsiella pneumoniae glutamine synthetase $(g \ln A)$ gene. Nucleic Acids Research 12, 7811-7830.

HENIKOFF, S. (1984). Unidirectional digestion with exonuclease III creates targeted breakpoints for DNA sequencing. Gene 28, 351-359.

HESPELL, R. B. (1984). Influence of ammonia assimilation pathways and survival strategy on rumen microbial growth. In Herbivore Nutrition in the Subtropics and Tropics, pp. 346-358. Edited by F. M. C. Gilchrist \& R. I. Mackie. Craighall: The Science Press.

Hill, R. T., Parker, J. R., Goodman, H. J. K., Jones, D. T. \& Woods, D. R. (1989). Molecular analysis of a novel glutamine synthetase of the anaerobe Bacteriodes fragilis. Journal of General Microbiology 135, 3271-3279. 
Holdeman, L. V. \& MoORe, W. E.C. (1972). Anaerobe Laboratory Manual. Blacksberg, USA: Virginia Polytechnic Institute and State University.

Janson, C. A., Kayne, P. S., Almassy, R. J., Grunstein, M. \& EISENBERG, D. (1986). Sequence of glutamine synthetase from Salmonella typhimurium and implications for the protein structure. Gene 6, 297-300.

Janssen, P., Jones, W. A., Jones, D. T. \& Woods, D. R. (1988). Molecular analysis and regulation of the $g \ln A$ gene of the Grampositive anaerobe Clostridium acetobutylicum. Journal of Bacteriology 170, 400-408.

Kumada, Y., Takano, E., Nagaoka, K. \& Thompson, C. J. (1990). Streptomyces hygroscopicus has two glutamine synthetase genes. Journal of Bacteriology 172, 5343-5351.

Lin, L. L., Rumbak, E., Zappe, H., Thomson, J. A. \& Woods, D. R. (1990). Cloning, sequencing and analysis of expression of a Butyrivibrio fibrisolvens gene encoding $\beta$-glucosidase. Journal of General Microbiology 136, 1567-1576.

MiLleR, J. H. (1972). Experiments in Molecular Genetics. Cold Spring Harbor, NY: Cold Spring Harbor Laboratory.

Nakano,Y., Chiaki, K., Takana, E., Kimura, K. \& Horikoshi, K. (1989). Nucleotide sequence of glutamine synthetase gene $(g \ln A)$ and its upstream region from Bacillus cereus. Journal of Biochemistry 106, 209-215.

Possot, O., Sibold, L. \& Aubert, J. P. (1989). Nucleotide sequence and expression of the glutamine synthetase structural gene, $g \ln A$, of the archaebacterium Methanococcus voltae. Research in Microbiology 140, 355-371.

Rawlings, D. E., Jones, W. A., O'Neill, E. G. \& Woods, D. R. (1987). Nucleotide sequence of the glutamine synthetase gene and its controlling region from the acidophilic autotroph Thiobacillus ferrooxidans. Gene 53, 211-217.

ReITZER, L. J. \& MagasaniK, B. (1985). Expression of $g \ln A$ in Escherichia coli is regulated at tandem promoters. Proceedings of the National Academy of Sciences of the United States of America 82 , 1979-1983.

RocheforT, D. A. \& Benson, D.R. (1990). Molecular cloning, sequencing and expression of the glutamine synthetase II ( $g \ln I I)$ gene from the actinomycete root nodule symbiont Frankia sp. strain CpII. Journal of Bacteriology 172, 5335-5342.

Sambrook, J., Fritsch, E. F. \& Maniatis, T. (1989). Molecular Cloning. A Laboratory Manual. Cold Spring Harbor, NY: Cold Spring Harbor Laboratory.
ShapiRo, B. M. \& Stadtman, E. R. (1968). 5'-Adenylyl-O-tyrosine. The novel phosphodiester of adenylylated glutamine synthetase from Escherichia coli. Journal of Biological Chemistry 243, 3769-3771.

Smith, C. J., Hespell, R. B. \& BRyant, M. P. (1981). Regulation of ammonia assimilatory enzymes and urease in Selenomonas ruminantium. Applied and Environmental Microbiology 42, 89-96.

Southern, J. A., Parker, J. R. \& Woods, D. R. (1986). Expression and purification of glutamine synthetase cloned from Bacteroides fragilis. Journal of General Microbiology 132, 2827-2835.

Southern, J. A., Parker, J. R. \& Woods, D.R. (1987). Novel structure, properties and inactivation of glutamine synthetase cloned from Bacteroides fragilis. Journal of General Microbiology 133, 2437-2446.

Strauch, M. A., Aronson, A. I., Brown, S. W., Schreier, H. J. \& SONENSHEIN, A. L. (1988). Sequence of the Bacillus subtilis glutamine synthetase gene region. Gene 71, 257-265.

STREICHER, S. L. \& TYleR, B. (1980). Purification of glutamine synthetase from a variety of bacteria. Journal of Bacteriology 142, 69-78.

Strydom, E., Mackie, R. I. \& Woods, D. R. (1986). Detection and characterization of extracellular proteases in Butyrivibrio fibrisolvens H17c. Applied Microbiology and Biotechnology 24, 214-217.

Tischer, E., DasSarma, S. \& Goodman, H. M. (1986). Nucleotide sequence of an alfalfa glutamine synthetase gene. Molecular and General Genetics 203, 221-229.

Toukdarian, A., Saunders, G., Selman-Sosa, G., Santero, E., WoOdLeY, P. \& KenNedY, C. (1990). Molecular analysis of the Azotobacter vinelandii glnA gene encoding glutamine synthetase. Journal of Bacteriology 172, 6529-6539.

Towbin, H., Staehelin, T. \& Gordon, J. (1979). Electrophoretic transfer of proteins from polyacrylamide gels to nitrocellulose sheets: procedure and some applications. Proceedings of the National Academy of Sciences of the United States of America 76, 4350-4354.

Tumer, N. E., Robinson, S. J. \& HaselkoRN, R. (1983). Different promoters for the Anabaena glutamine synthetase gene during growth using molecular or fixed nitrogen. Nature, London 306, 337-342.

Walker, J. E., Saraste, M., Runwick, M. J. \& Gay, N. J. (1982). Distantly related sequences in the $\alpha$ - and $\beta$-subunits of ATPsynthetase, myosin, kinases and other ATP-requiring enzymes and a common nucleotide binding fold. EMBO Journal 1, 945-951.

ZABEAU. M. \& STANLEY, K. K. (1982). Enhanced expression of cro- $\beta$ galactosidase fusion proteins under the control of the $\mathrm{P}_{\mathrm{R}}$ promoter of the bacteriophage lambda. EMBO Journal 1, 1217-1224. 